Research Article

\title{
Determinant of Mother's Health Promotional Measures Practice of Infant with Age 6-12 Months in a Tertiary Hospital of Nepal
}

\author{
Chet Kant Bhusal \\ Department of Community Medicine, Universal College of Medical Science and Teaching Hospital, Tribhuvan University, \\ Bhairahawa, Rupandehi, Nepal
}

Correspondence should be addressed to Chet Kant Bhusal; bhusalck3112@gmail.com

Received 30 December 2020; Revised 22 May 2021; Accepted 28 May 2021; Published 10 June 2021

Academic Editor: Diego A. S. Silva

Copyright $(2021$ Chet Kant Bhusal. This is an open access article distributed under the Creative Commons Attribution License, which permits unrestricted use, distribution, and reproduction in any medium, provided the original work is properly cited.

Background. Promotion of health is vital for the optimal growth and development of every infant. Globally, many infants died due to common problems such as diarrhoea and respiratory infection; most of these problems are related to inadequate breast feeding, improper complimentary feeding, lack of immunization, and home accident. Infant and child health status depends upon mothers' knowledge and practice regarding health promotional measures. This study aimed to determine practice and its determinants regarding health promotional measures of infant with 6-12 months age amongst the mothers attending Pediatrics Outpatient Department of Universal College of Medical Science and Teaching Hospital, Bhairahawa, Rupandehi, Nepal. Methods. Hospital-based cross-sectional study was conducted in Universal College of Medical Science, Bhairahawa, Rupandehi, Nepal, among 414 mothers attending pediatrics outpatient department from September 2019-March 2020. Purposive sampling technique was used to select mothers of infants aged 6-12 months. Bivariate analysis was used primarily to assess the association between dependent and independent variables. Variables which were associated in bivariate analysis with $p<0.05$ were entered into a multivariable logistic regression model to identify associated factors of health promotional measures. The goodness of fit of multivariate logistic regression was checked by Nagelkerke $R$ square and variation inflation factor. Results. The mean age and family size was $25.89 \pm 4.81$ years and $5.94 \pm 2.48$, respectively. A total of $71.5 \%$ mothers have good practice of health promotional measures. Mothers from Dalit caste (adjusted odds ratio $=0.04$, confidence interval: $0.005-0.30$ ), mothers with below school leaving certificate education $(\mathrm{AOR}=0.08, \mathrm{CI}: 0.02-0.27)$, fathers engaged in nonagricultural work $(\mathrm{AOR}=7.21, \mathrm{CI}: 2.59-20.11)$, birth space of index child greater than 2 years $(\mathrm{AOR}=12.88, \mathrm{CI}$ : 3.49-47.58), and family monthly income greater than 20000 Nepalese rupees $(A O R=3.29$, CI: 1.16-13.32 were significantly associated with good practice of health promotional measures. Conclusions. More than one-fourth of the mothers have poor practice of health promotional measures. Ethnicity, mothers' education, fathers' occupation, birth space of index child, and family monthly income were found to be independent determinants of practice of health promotion measures. Thus, policy makers should provide specific education regarding health promotional measures to both parents.

\section{Introduction}

The infancy is period when child attain rapid physical, social growth, and development. Promotion of optimum health of infancy includes nutrition, growth monitoring, sleep and activity, prevention of infection, accidents, play, and stimulation and anticipatory guidance [1]. The infants are dependent and susceptible for permanent effects of risky and vulnerable activities; hence, the need of health maintenance has greater importance [2]. Health promotion is the process of enabling people to increase control over and to improve their health [3]. Mother is the significant person for the promotion of psychosocial development of infants and children. Healthcare providers should assist the parents to make decisions and to take care of their children according to their individual child's needs [4]. Maternal knowledge 
regarding child development has influence on the way mothers act together with their offspring [5]. The major components of the health promotion of infant are breastfeeding, complementary feeding, immunization, and accident [1]. Breastfeeding is widely regarded as the best form of infant feeding, with many advantages for both the infants and the mothers [6]. Exclusive breastfeeding is characterized as a mother who breastfeeds her child exclusively for six months without supplementation, not even water with exception of oral rehydration solution, drops, or syrups consisting of vitamins, minerals supplements, or medicines [7]. Reduced morbidity related to gastrointestinal illness is a significant benefit with exclusive breastfeeding from 4 to 6 months. Perhaps most notably, exclusive breastfeeding has been linked to a lower infant mortality rate [8]. The complementary feeding is a critical window for reducing stunting, wasting, overweight, and obesity, as well as optimizing long-term growth and health [9]. Immunization allows for the promotion of coordinated care and the improvement of recipients' overall health and wellbeing [10]. Children's accidents at home are rapidly being recognized as a public health issue that could be avoided with greater awareness, good practices, and changes to the home climate [11].

Evidence shows that only about $35 \%$ of infants worldwide are exclusively breastfed during the first four months of life; complementary feeding frequently begins too early or too late, and foods are often nutritionally inadequate and unsafe [12]. A study of infant feeding practices of mothers in an urban area of Pokhara Nepal revealed that only $43.5 \%$ of the mothers initiated breastfeeding within one hour of birth and $60.5 \%$ were practicing exclusive breastfeeding at 5 months [13].

Poor quality complementary foods with low-nutrient density and inappropriate feeding practices have been identified among the major causes of malnutrition in young children. In many developing countries, complementary foods are introduced too early or too late, and the quality and quantity of the foods are insufficient, leading to a great risk of nutritional deficiencies during the second half of infancy [14]. Meeting minimum standards of dietary quality is a challenge in Nepal. Children were not receiving complementary foods at the right age (either too early or too late), were not fed frequently enough, and the quality of the food might be inadequate [15]. Infant mortality rate (IMR) of the world is $36.58 / 1000$ live births [16]. Globally, 5.2 million children under the age of 5 years and 2.4 million newborns died in the first month of life in 2019 [17]. More than half of these early child deaths are due to conditions that could be prevented or treated with access to simple, affordable interventions like vaccination. Though more than 1 billion children vaccinated over the last decade, global vaccination coverage has stuck at $85 \%$ with no significant changes during the past year [18]. The most common causes of death of the infants are diarrhoea and respiratory infection. The problems are related to inadequate breast feeding, lack of knowledge in complimentary feeding, and lack of immunization. The other most common cause of death is home accident. Mothers can prevent or minimize these problems by proper care of infants [16].

In order to maintain the proper health status of infant, proper infant health promotion is necessary. Mother has main parenting role of her infant rather than father, as she spends almost all time with her infant. Health promotion of infant depends upon the level of practice of mother. Although growing literatures are found on various aspects of breast feeding, complementary feeding, immunization, and prevention of accidents among infants, there are very few studies carried out to investigate the determinants of practice of health promotional measures of infant among mothers. Therefore, this study was conducted to identify the practice and different determinants affecting practices of health promotional measures of infant with 6-12 months age among the mothers attending Pediatrics Outpatient Department (OPD) of Universal College of Medical Science and Teaching Hospital (UCMS-TH), Bhairahawa, Rupandehi, Nepal.

\section{Materials and Methods}

\subsection{Study Design and Source of Population.} Hospital-based cross-sectional study was conducted in Universal College of Medical Science, Bhairahawa, Rupandehi, Nepal, from September 2019-March 2020. Mothers having child aged six to twelve months attending pediatrics OPD of UCMS were included in the study. Similarly, mothers with severe mental problems who have no willingness to participate were excluded from the study.

\subsection{Sample Size Determination and Sampling Technique.} The sample size of the study was 414 which was calculated by using formula $N=Z^{2} p q / L^{2}$ with $95 \%$ level of confidence interval, critical value $Z=1.96,5 \%$ margin of error, and $56.81 \%$ mothers fed their children complementary food of appropriate consistency [19]. Hence, $N=Z^{2} p q / d^{2}=(1.96)^{2} \times(0.57) \times$ $(0.43) /(0.05)^{2}=376$. Adding $10 \%$ nonresponse rate, the final sample size $(n)=414$. A nonprobability purposive sampling technique was used to select the sample. Those respondents who were attending pediatrics OPD of Universal College of Medical Science and Teaching Hospital were judged at first whether they can fulfil the inclusion criteria, and they were selected purposively after taking written informed consent.

2.3. Data Collection Procedures and Validity. A set of semistructured questionnaire was formulated as data collection tools to collect the information of the respondents. Initially, the questionnaire was prepared in English and then translated in to Nepali language. Nepali questionnaire was retranslated to English to find consistency of question. Pretesting of the questionnaire was done among $10 \%$ of the sample in nearby private clinic of Bhairahawa, Nepal. Twoday training was provided to four pediatric residence doctors and one final year bachelor in public health student of UCMS. Face-to-face interview was conducted among selected mothers. All the filled questionnaires were reviewed and checked by the principal investigator on regular basis. 
2.4. Data Processing and Analysis. Collected data were followed by a cross-check to ensure all the questions have been filled correctly. Data checking, compiling, and editing were carried out manually by the researcher. Collected data were entered into Microsoft Excel, and SPSS software version 22 was used to analyze the data. Simple frequency tables, cross tables, and mean tables had been used to present data related to the study. Relationship of the practice level regarding health promotional measures with different independent variables was compared and tested using the chi-square test, and significance will be considered when $p<0.05$. Furthermore, crude odds ratio and confidence interval were calculated using binary logistic regression. Those variables which were found significantly associated in binary logistic regression with dependent variables were entered into the multivariate logistic regression model to find the adjusted odds ratio and confidence interval for the final determinants of health promotional measures of infants. The goodness of fit of multivariate logistic regression was checked by Nagelkerke $R$ square, and multicollinearity was checked by the variation inflation factor. The value of Nagelkerke $R$ square was 0.449 ; which showed that goodness of fit is adequate. Similarly, VIF of all independent variables was less than 10 which lies in the range 1.01-2.04, so multicollinearity was not available among independent variables. After testing this, multivariate logistic regression was calculated to find the net effect of independent variables in mother's health promotional measures practice of infants with the 6-12 months age group. Then, adjusted odds ratio (AORs) was estimated, and their corresponding value at 95\% confidence intervals was calculated.

2.5. Setting. The present study was conducted in Universal College of Medical Science and Teaching Hospital, Bhairahawa, Rupandehi district of Nepal. Rupandehi district of Lumbini Zone comes under the western development region. Rupandehi district is situated in the lovely lap of the Chure range and surrounded by Palpa on the north, India on the south, Kapilvastu on the west, and Nawalparasi on the east. The total area of this district is 1172 square kilometer. The geographical position of the district is $83010^{\prime \prime}$ to $83030^{\prime \prime}$ longitudes in the east and $27010^{\prime \prime}$ to $27045^{\prime \prime}$ latitude in the north. The total surface area of the district is 141,340 ha with an altitude ranging from $95 \mathrm{~m}$ to $1219 \mathrm{~m}$ above the sea level [20]. According to CBS 2012, district has total population of $8,80,196$ [21].

Universal College of Medical Sciences (UCMS) is a tertiary level hospital, established in the year 1998 with the affiliation of T.U and recognized by Nepal Medical Council (NMC), and considered as the pioneer institute in Nepal in the field of medicine and dentistry.

2.6. Measurement of Practice regarding Health Promotional Measures. Health promotion measures in this study referred to those acts or activities of the mother which promote the health of infant which comprises of exclusive breastfeeding, complimentary feeding, immunization, and prevention of accident. There were 20 questions related to practice regarding health promotional measure of infant. It consisted of four subscales which comprised of practice regarding breastfeeding, practice regarding complementary feeding, practice regarding immunization, and practice regarding prevention of accidents each consisting of $7,6,3$, and 4 items, respectively. In the each subscale, single response items were only included. So the score in each subscale was 7 , 6,3 , and 4 , respectively. The total score of this section was 20 . The practice score was categorized as good practice, $\geq 50 \%$ of total score, and poor practice, $<50 \%$ total score.

2.7. Ethical Consideration and Informed Consent. This study received ethical approval from Institutional Ethical Review Board of Universal College of Medical Science and Teaching Hospital, Bhairahawa, Rupandehi, Nepal (UCMS/IRC/126/ 19). Moreover, all the participants were fully informed about the nature of study, research objectives, privacy, and confidentiality of the collected information. Prior to interview, written informed consent was taken from the respondents. Only those respondents who voluntarily agree to participate were involved in the study. All study participants were informed of their right to refuse participation and to leave the interview at any time. The researcher had followed the principals of justice, human dignity, and physical wellbeing of the respondents. The respondent and their thoughts were respected.

\section{Results}

The mean age and family size was $25.89 \pm 4.81$ years and $5.94 \pm 2.48$, respectively. More than half $(53.9 \%)$ of respondents had nuclear family. Four-fifths $(80.2 \%)$ of the respondents were Hindu. More than four-fifths (89.1\%) of the respondents infant lived with both mothers and father in family. Nearly two-thirds (64.7\%) of the respondent had two or less than two living children. More than two-thirds (69.8\%) of the respondents' family earned less than or equal to twenty thousand Nepalese rupees (NRs) per month. Nearly one-fourth $(23.7 \%)$ of the infants' mothers had received education of secondary and above intermediate levels. About half (49.3\%) of the infants' father had received education of intermediate and above levels. About half (49.5\%) of infants' mothers were housewives. About two-fifths (39.4\%) of infants' father were engaged in small scale business (Table 1).

Regarding practice of breast feeding more than fourfifths $(87.4 \%)$ of the infant's mother have fed colostrum to their babies, whereas nearly one-fifth (19.6\%) of the infant's mother have fed anything else than breastfeeding after birth. Likewise, regarding complementary feeding, most (95.2\%) of the infant's mother started complementary feeding with lito, mashed cereals, and fruits; similarly, very less (10.6\%) of the infant's mother have fed at least three to four items of food at a time. Majority (93.2\%) of the infant's mother had immunized their babies as per national immunization schedule and more than half (55.6\%) of the infant's mother had taken their babies to hospital when fever arise after vaccination. About three-fourths (76.3\%) of the infant's 
TABLE 1: Background related characteristics of mothers of infant with age group 6-12 months in a tertiary hospital of Nepal.

\begin{tabular}{|c|c|c|}
\hline General characteristics & $\begin{array}{l}\text { Frequency } \\
(n=414)\end{array}$ & Percentage \\
\hline \multicolumn{3}{|l|}{ Caste/ethnicity } \\
\hline Brahmin/Chhetri & 145 & 35.0 \\
\hline Madeshi & 89 & 21.5 \\
\hline Dalits & 28 & 6.8 \\
\hline Newar & 23 & 5.6 \\
\hline Janjati & 59 & 14.3 \\
\hline Muslim & 70 & 16.9 \\
\hline \multicolumn{3}{|l|}{ Religion } \\
\hline Hindu & 332 & 80.2 \\
\hline $\begin{array}{l}\text { Non-Hindu (Christian and } \\
\text { Muslim) }\end{array}$ & 82 & 19.8 \\
\hline \multicolumn{3}{|l|}{ Types of family } \\
\hline Nuclear & 223 & 53.9 \\
\hline Joint or extended & 191 & 46.1 \\
\hline \multicolumn{3}{|l|}{ Education of mother } \\
\hline Illiterate and informal class & 81 & 19.6 \\
\hline Primary & 44 & 10.6 \\
\hline Secondary & 98 & 23.7 \\
\hline SLC & 93 & 22.5 \\
\hline Intermediate and above & 98 & 23.7 \\
\hline \multicolumn{3}{|l|}{ Education of father } \\
\hline Illiterate and informal class & 33 & 8.0 \\
\hline Primary & 41 & 9.9 \\
\hline Secondary & 63 & 15.2 \\
\hline SLC & 73 & 17.6 \\
\hline Intermediate and above & 204 & 49.3 \\
\hline \multicolumn{3}{|l|}{ Occupation of father } \\
\hline Agriculture & 87 & 21.0 \\
\hline Small scale business & 163 & 39.4 \\
\hline $\begin{array}{l}\text { Service (government and } \\
\text { private) }\end{array}$ & 134 & 32.4 \\
\hline Wage labor & 14 & 3.4 \\
\hline Foreign labor & 16 & 3.9 \\
\hline \multicolumn{3}{|c|}{ Birth space of index child $(n=357)$} \\
\hline$\leq 2$ years & 272 & 65.7 \\
\hline$>2$ years & 85 & 20.5 \\
\hline \multicolumn{3}{|l|}{ Earning status (cash money) } \\
\hline Earning & 352 & 85 \\
\hline No earning & 62 & 15 \\
\hline \multicolumn{3}{|c|}{ Family monthly income in Nepalese rupees (NRs) } \\
\hline$\leq 20000$ & 289 & 69.8 \\
\hline$>20000$ & 125 & 30.2 \\
\hline
\end{tabular}

SLC, school leaving certificate.

mother avoid small piece of toys and other things in order to prevent from ingestion injury, and similarly, more than onefourth $(33.3 \%)$ of the infant's mother does not leave child alone to prevent them from home accidents (fall injury) (Table 2).

About three-fourths (71.5\%) of the mothers' of infant have good practice regarding health promotional measure (Table 3).

Table 4 provides sociodemographic, socioeconomic, and child-related factors associated with the practice level of health promotional measures. Variables such as ethnicity, religion, mother's education, father's education, father's occupation, birth space of index child, and family monthly income were found statistical significant with $p$ value lesser than equal to 0.05 in bivariate analysis, and these variables were entered into the multivariate logistic regression analysis model which identified ethnicity, mother's education, father's occupation, birth space of index child, and family monthly income as associated factors with the practice level of health promotional measures. Mothers who were from Dalit caste were $96 \%$ less likely $(\mathrm{AOR}=0.04$, $\mathrm{CI}=0.005-0.30)$ to have good practice regarding health promotional measures than those who were from Brahmin/ Chhetri caste. The odds of having good practice regarding health promotional measures were reduced by $92 \%$ $(\mathrm{AOR}=0.08, \mathrm{CI}=0.02-0.27)$ among mothers having educational backgrounds below school leaving certificate (SLC) than their counterparts who were from illiterate backgrounds. Regarding the father occupation, the odds of having good health promotional measures were 7.21 more likely ( $\mathrm{AOR}=7.21, \mathrm{CI}=2.59-20.11$ ) among fathers who were engaged in other than agriculture work than those who were involved in agriculture work. Mothers whose index child had birth space of greater than 2 years were 12.88 times more likely $(\mathrm{AOR}=12.88, \mathrm{CI}=3.49-47.58)$ to have good practice of health promotional measures than their counterparts. Similarly, those respondents whose monthly family income was greater than NRs 20000 were 3.29 times more likely $(\mathrm{AOR}=3.29, \mathrm{CI}=1.16-13.32)$ to have good practice regarding health promotional measures than those whose family income was lesser than equal to NRs 20000 (Table 4).

\section{Discussion}

Ethnicity, mother's education, father's occupation, birth space of index child, and family monthly income were associated factors of good practice of health promotional measures in this study. Mothers from Dalit caste have poor practice on health promotional measures; this might be due to that Dalit is lower caste and Nepalese society is higher caste dominant society. Mothers having below SLC level education have poor practice regarding health promotional measures. Likewise, fathers who were engaged in nonagricultural work have practiced good health promotional measures.

More than two-thirds of the infant's mothers had good level of practice regarding health promotional measures in this study; however, in contrast to this study, another study conducted in Nepal found that less than one-third of the mothers had good level of practice [22]. This disparity might be due to the divergence scoring system for measuring the health promotional measures.

More than three-fourth of the infants in the current study were fed with breast milk during the survey; however, lower proportion of infants with 6-12 months were fed with breastfeeding in the study conducted in Italy [23]. This difference might be due to different study setting and methodology adopted by two different studies. The present study found slightly less than three-fourths of the babies were exclusively breast fed (EBF) for complete 6 months of age. However, several other studies conducted in different 
TABLE 2: Mothers' practice regarding health promotional measure of infant with age group 6-12 months in a tertiary hospital of Nepal.

\begin{tabular}{|c|c|c|}
\hline Practice regarding health promotional measures & Number $(n=414)$ & Percentage \\
\hline \multicolumn{3}{|l|}{ Breast feeding } \\
\hline Feeding anything else than breastfeeding after birth & 81 & 19.6 \\
\hline Feeding colostrum to the baby & 362 & 87.4 \\
\hline Breastfeeding within an hour of birth & 223 & 53.9 \\
\hline Exclusive breastfeeding for complete 6 months & 304 & 73.4 \\
\hline Recently feeding breast milk & 323 & 78.0 \\
\hline Burping baby after feeding breast milk & 232 & 56.0 \\
\hline Wiped breast with clean cloth before breast feeding & 134 & 32.4 \\
\hline \multicolumn{3}{|l|}{ Complementary feeding } \\
\hline Started complementary feeding after 6 months & 244 & 58.9 \\
\hline Started complementary feeding with lito, mashed cereals, and fruits & 394 & 95.2 \\
\hline Continuation of breast feeding with complementary feeding & 366 & 88.4 \\
\hline Washing hands with soap and water before giving food & 257 & 62.1 \\
\hline Feeding at least three to four items of food at a time & 44 & 10.6 \\
\hline Feeding according to infant wish during their sickness & 85 & 20.5 \\
\hline \multicolumn{3}{|l|}{ Immunization } \\
\hline Immunized baby as per national immunization schedule & 386 & 93.2 \\
\hline Taking baby to hospital when fever arise after vaccination & 230 & 55.6 \\
\hline Taking baby to hospital in any side effect after vaccination & 359 & 86.7 \\
\hline \multicolumn{3}{|l|}{ Prevention of accidents } \\
\hline Keep burned part on water in home during child burn & 224 & 54.1 \\
\hline Avoid small piece of toys and other things in order to prevent from ingestion injury & 316 & 76.3 \\
\hline Does not leave infant alone to prevent from home accident (fall injury) & 138 & 33.3 \\
\hline Some members supervised infant to prevent during playing & 249 & 60.1 \\
\hline
\end{tabular}

TABLE 3: Level of practice regarding mother's health promotional measures of infant with age group 6-12 months in a tertiary hospital of Nepal.

\begin{tabular}{lcc}
\hline Characteristics & Frequency $(n=414)$ & Percentage \\
\hline Poor practice & 118 & 28.5 \\
Good practice & 296 & 71.5 \\
Total & 414 & 100.0 \\
\hline
\end{tabular}

parts of the Nepal and other countries such as Nepal Demographic and Health Survey [24], and other studies conducted in Nepal [25-27], south India [28], Trongsa District, Bhutan [29], northwest Ethiopia [30], and Jimma town, southwest Ethiopia [31] reported a lower proportion of the babies were exclusively breast fed for 6 months than the present study. In contrast to this study, another study conducted in Chepang communities of Makawanpur district, Nepal [32], and Northwest Ethiopia [33] found that higher proportion of the babies were exclusive breast fed until 6 months. These differences might be due to different study setting, methodology adopted, change in time, and advancement of educational materials as compared to previous time. Nearly about one-fifth of the mothers fed prelacteal after their baby birth which is in line with another study conducted in Bhaktapur, Nepal, [34] and rural Bangladesh [35]. However, in contrast to this study, other studies such as studies carried out in Nepal [36, 37], Kinshasa, DR Congo [38], and Nairobi, Kenya [39], found higher proportion of mothers give supplementation prior to breast feeding initiation. This difference might be due to different study setting and level of awareness among respondents. Majority (87.4\%) of the mothers in this study fed colostrum to their baby, which is in line with another national study conducted in Nepal [40], in Bhaktapur, Nepal [34], and in India [41]. More than half of the respondents in this study initiated breastfeeding within the first hour after birth, which is in line with the national level data of Nepal demographic and Health Survey 2016 [24] and another study conducted in Nepal [34]. However, another study conducted in western Nepal found that lower portion of mothers initiated their breast feeding to their babies within an hour [42]. This divergence might be due to the level of respondents as previous study was carried out in slum area. Less than three-fifths of the mothers in this study did burping to their babies after feeding breast milk; however, in contrast to this study, another study conducted in India found threefourths of the mothers practiced burping after feeding breast milk to their babies [43]. This difference might be due to different study setting and methodology adopted in two different studies.

The present study revealed that around three-fifths of the mothers started complementary feeding after 6 months which is in line with the study conducted in Nepal [21, 44], south India [45], and Ethiopia [46]. However, in contrast to this study, another study conducted in Nepal found only around one-fifth and study conducted in Kosova [47] found around two-fifths of the mother initiated complementary feeding after 6 months of age [48]. This divergence might be due to the reason that previous study was conducted in community setting and this study is in hospital setting. Majority of the respondents in the present study continued feeding their breast milk along with complimentary feeding to their children which is in line with another cross-sectional study conducted in Chepang communities of Nepal [32]. 
TABLE 4: Determinants of mother's practice level of health promotion measures of infant with age group 6-12 months in a tertiary hospital of Nepal.

\begin{tabular}{|c|c|c|c|c|c|}
\hline \multirow{2}{*}{ Characteristics } & \multicolumn{2}{|c|}{ Practice level (\%) } & \multirow{2}{*}{$P$ value } & \multirow{2}{*}{${ }^{\mathrm{a}} \mathrm{COR} 95 \% \mathrm{CI}$} & \multirow{2}{*}{${ }^{\mathrm{b}} \mathrm{AOR} 95 \% \mathrm{CI}$} \\
\hline & Poor practice & Good practice & & & \\
\hline \multicolumn{6}{|l|}{ Ethnicity } \\
\hline Brahmin/Chhetri & $41(28.3)$ & $104(71.7)$ & & 1 & 1 \\
\hline Madeshi & $22(24.7)$ & $67(75.3)$ & $0.028^{*}$ & $1.20(0.66-2.19)$ & $1.17(0.52-2.63)$ \\
\hline Dalits & $8(28.6)$ & $20(71.4)$ & & $0.99(0.40-2.42)$ & $0.04(0.005-0.30)$ \\
\hline Newar & $4(17.4)$ & $19(82.6)$ & & $1.87(0.60-5.84)$ & $1.24(0.22-7.17)$ \\
\hline Janjati & $12(20.3)$ & $47(79.7)$ & & $1.54(0.74-3.20)$ & $3.36(0.87-12.99)$ \\
\hline Muslim & $31(44.3)$ & $39(55.7)$ & & $0.50(0.27-0.90)$ & $0.14(0.01-1.89)$ \\
\hline \multicolumn{6}{|l|}{ Religion } \\
\hline Hindu & $82(24.7)$ & $250(75.3)$ & & 1 & 1 \\
\hline Non-Hindu & $36(43.9)$ & $46(56.1)$ & $0.001^{*}$ & $0.42(0.25-0.69)$ & $5.35(0.43-66.42)$ \\
\hline \multicolumn{6}{|l|}{ Types of family } \\
\hline Nuclear & $66(29.6)$ & $157(70.4)$ & & 1 & - \\
\hline Jointed and extended & $52(27.2)$ & $139(72.8)$ & 0.594 & $1.12(0.73-1.73)$ & \\
\hline \multicolumn{6}{|l|}{ Mother's education } \\
\hline Illiterate and informal & $21(25.9)$ & $60(74.1)$ & & 1 & 1 \\
\hline Below SLC & $54(38.0)$ & $88(62.0)$ & & $0.57(0.31-1.04)$ & $0.08(0.02-0.27)$ \\
\hline SLC and above & $43(22.5)$ & $148(77.5)$ & $0.007^{*}$ & $1.21(0.66-2.20)$ & $0.09(0.02-0.37)$ \\
\hline \multicolumn{6}{|l|}{ Father's education } \\
\hline Illiterate and informal & $18(54.5)$ & $15(45.5)$ & & 1 & 1 \\
\hline Below SLC & $40(38.5)$ & $64(61.5)$ & $<0.001^{*}$ & $1.92(0.87-4.23)$ & $1.10(0.25-4.85)$ \\
\hline SLC and above & $60(21.7)$ & $217(78.3)$ & & $4.34(2.07-9.12)$ & $3.24(0.70-14.91)$ \\
\hline \multicolumn{6}{|l|}{ Mother's occupation } \\
\hline Housewives & $53(25.9)$ & $152(74.1)$ & & 1 & - \\
\hline Other than housewives & $65(31.1)$ & $144(68.9)$ & 0.237 & $0.77(0.50-1.19)$ & \\
\hline \multicolumn{6}{|l|}{ Father's occupation } \\
\hline Agriculture & $38(43.7)$ & $49(56.3)$ & & 1 & 1 \\
\hline Other than agriculture & $80(24.5)$ & $247(75.5)$ & $<0.001^{*}$ & $2.39(1.46-3.92)$ & $7.21(2.59-20.11)$ \\
\hline \multicolumn{6}{|l|}{ Number of living children } \\
\hline$\leq 2$ children & $68(25.4)$ & $200(74.6)$ & 0.056 & 1 & - \\
\hline$>$ children & $50(34.2)$ & $96(65.8)$ & & $0.65(0.42-1.01)$ & \\
\hline \multicolumn{6}{|l|}{ Birth space (index child) } \\
\hline$\leq 2$ years & $85(31.3)$ & $187(68.8)$ & & 1 & \\
\hline$>2$ years & $5(5.9)$ & $80(94.1)$ & $<0.001^{*}$ & $7.27(2.84-18.60)$ & $12.88(3.49-47.58)$ \\
\hline \multicolumn{6}{|l|}{ Earning status } \\
\hline Earning & $94(26.7)$ & $258(73.3)$ & & 1 & - \\
\hline No earning & $24(38.7)$ & $38(61.3)$ & 0.054 & $0.58(0.33-1.01)$ & \\
\hline \multicolumn{6}{|c|}{ Family monthly income (NRs) } \\
\hline Earning $\leq 20000$ & $103(35.6)$ & $186(64.4)$ & & 1 & 1 \\
\hline$>20000$ & $15(12.0)$ & $110(88.0)$ & $<0.001^{*}$ & $4.061(2.25-7.33)$ & $3.29(1.16-13.32)$ \\
\hline
\end{tabular}

*Significant at $p<0.05,1$, reference category. ${ }^{\mathrm{a}}$ Crude odds ratio. ${ }^{\mathrm{b}}$ Adjusted odds ratio.

The present study revealed that more than three-fifths of the respondents washed their hand with soap and water before giving food to their infants; however, in contrast to this study, another study conducted in Singapore found lower portion of the mothers washed their hands before feeding their babies [49]. This divergence might be due to difference in study setting and level of community respondents in the previous study.

In this study, majority of the respondents immunized their babies as per National Immunization Schedule; however, the national level survey reported lower percentage of children aged 12-23 months had received all basic vaccinations [24]. The national data suggested high dropout rates have been recorded in the Terai area, which has a high population density [21]. This divergence might be due to age differences of children. More than four-fifths of the respondents took their babies to hospital during any side effect that arises after vaccination; however, in contrast to this study, another study conducted in Kathmandu, Nepal, found that lower proportion of the respondents took their babies to hospital [22]. This might be due higher education level of the respondents in this study.

The present study revealed that one-third of the respondents did not leave their infant alone to prevent from home accidents (fall injury) which is not consistent with another study conducted in Bara district, Nepal, where 
large portion of mothers do not leave their small child alone or without guarding [50]. This might be due to different study setting in these two studies. More than three-fourths of the respondents in this study avoid small piece of toys and other things in order to prevent their children from ingestion injury; however, another study conducted in Kathmandu, Nepal, found lower proportion of the mothers avoid such things to prevent their children from ingestion injury [22]. This might be due to the different study setting and higher education level of the respondents in this study.

The present study revealed that mothers' ethnicity was significantly associated with the practice of health promotional measures which is in line with the study conducted in Nairobi, Kenya, where mothers' ethnicity was significantly associated with suboptimal infant breastfeeding and feeding practices [39]. Mothers' education in this study was significantly associated with practice of health promotional measures which is in accordance with the study conducted in Chepang communities in Nepal [32] where mothers education was associated with infant and young child feeding, in Ethiopia [51] where mother education is significantly associated with exclusive breastfeeding practice, in Nairobi, Kenya [39] where suboptimal infant breastfeeding and feeding practices was significantly associated with mothers education. Fathers' occupation in this study was significantly associated with practice of health promotional measures which is in accordance with several other studies conducted in Ethiopia $[46,52]$ where fathers' occupation was positively associated with appropriate weaning practice of infants. Family' monthly income in this study was significantly associated with practice of health promotional measures which is in agreement with the study conducted in Bara, Nepal [50], where exclusive breastfeeding and prevention of childhood accident was significantly higher among richest household.

4.1. Strengths and Limitations of the Study. The strength of this study is it to provide the aggregate result of mother's health promotional measures including various components such as breastfeeding, especially exclusive breastfeeding, complementary feeding, immunization, and home accident of infants with age group 6-12 months. The limitation of the study is that it was conducted in only one tertiary hospital of Nepal, and purposive sampling was used as sampling technique.

\section{Conclusions}

More than one-fourth of the mothers have poor practice of health promotional measures. Ethnicity, mothers' education, fathers' occupation, birth space of index child, and family' monthly income were found to be independent determinants of practice of health promotion measures. In this context, it is recommended that administrators and policy makers should provide specific education regarding health promotional measures including breast feeding, complementary feeding, immunization, and prevention of accidents to both the parents focusing on rural area.
Abbreviations
AOR: $\quad$ Adjusted odds ratio
CI: $\quad$ Confidence interval
OPD: Outpatient department
OR: $\quad$ Odds ratio
SD: $\quad$ Standard deviation
SLC: $\quad$ School leaving certificate
SPSS: $\quad$ Statistical Package for the Social Sciences
UCMS- Universal College of Medical Science and
TH: $\quad$ Teaching Hospital.

\section{Data Availability}

The data used to support the findings of this study are available from the corresponding author upon request.

\section{Conflicts of Interest}

The author declares that there are no conflicts of interest.

\section{Acknowledgments}

The author would like to acknowledge Universal College of Medical Sciences and Teaching Hospital for necessary administrative arrangement by providing financial support for the study and express his gratitude to pediatric residents Dr. Ashraya Kedria, Dr. Sanjeev Shah, Dr. Astha Poudel, and Dr. Ranjana Sharma and final year Bachelor in Public Health student Ms. Ankita Kunwar for their support in data collection. The author would also like to remember all participants for their valuable time and support for providing inevitable information for the study.

\section{References}

[1] T. Shrestha, Essential Child Health Nursing, Medhavi Publication, Kathmandu, Nepal, 2nd edition, 2016.

[2] Peggyl and China, Infants and Early Childhood, Childhood Maintenance, The CV Mosby Company, 2nd edition, 1997.

[3] World Health Organization, Health Promotion, World Health Organization, Geneva, Switzerland, 2017, http://www.who. int/topics/health_promotion/en/.

[4] P. Dutta, Peadiatric Nursing, Jaypee Brothers Medical Publishers LTD, New Delhi, India, 3rd edition, 2014.

[5] F. Al-Maadadi and A. Ikhlef, "What mothers know about child development and parenting in Qatar," The Family Journal, vol. 23, no. 1, pp. 65-73, 2015.

[6] D. A. M. Al Juaid, C. W. Binns, and R. C. Giglia, "Breastfeeding in Saudi arabia: a review," International Breastfeeding Journal, vol. 9, no. 1, pp. 1-9, 2014.

[7] H. Nishimura, K. Krupp, S. Gowda, V. Srinivas, A. Arun, and P. Madhivanan, "Determinants of exclusive breastfeeding in rural south India," International Breastfeeding Journal, vol. 13, no. 1, pp. 40-47, 2018.

[8] A. Motee, D. Ramasawmy, P. Pugo-Gunsam, and R. Jeewon, "An assessment of the breastfeeding practices and infant feeding pattern among mothers in Mauritius," Journal of 
Nutrition and Metabolism, vol. 2013, Article ID 243852, 8 pages, 2013.

[9] K. F. Michaelsen, L. Grummer-Strawn, and F. Bégin, "Emerging issues in complementary feeding: Global aspects," Maternal \& Child Nutrition, vol. 13, Article ID e12444, 2017.

[10] WHO and Immunization WHO, Do Immunization in Practice: A Practical Guide for Health Staff, World Health Organization, Geneva, Switzerland, 2015.

[11] M. Nour, W. Alharbi, S. Alawneh et al., "Knowledge, attitude and practices of mothers towards home accident among children," Makkah, KSA. European Journal of Phamaceuticalans Medical Research, vol. 5, no. 2, pp. 139-147, 2018.

[12] WHO, Global Strategy for Infant and Young Child Feeding, WHO, Geneva, Switzerland, 2003.

[13] S. H. Subba, T. S. Chandrashekhar, V. S. Binu, H. S. Joshi, M. S. Rana, and S. B. Dixit, "Infant feeding practices of mothers in an urban area in Nepal," Kathmandu University Medical Journal (KUMJ), vol. 5, no. 1, pp. 42-47, 2007.

[14] V. Owino, B. Amadi, M. Sinkala, S. Filteau, and A. Tomkins, "Complementary feeding practices and nutrient intake from habitual complementary foods of infants and children aged 6-18 months old in Lusaka, Zambia," African Journal of Food, Agriculture, Nutrition and Development, vol. 8, no. 1, pp. 28-47, 2008.

[15] GON/MOHP/DOHS, Tracking Progress on Child and Maternal Nutrition in Nepal: A Survival and Development Priority, UNICEF, Geneva, Switzerland, 2010.

[16] The World Fact Book 2016, Central Intelligence Agency, https://www.cia.gov/library/publications/download/.

[17] WHO Facts sheet, "Children: improving survival and wellbeing," 2020, https://www.who.int/news-room/fact-sheets/ detail/children-reducing-mortality.

[18] WHO Facts Sheet 2020, Immunization Coverage, https:// www.who.int/en/news-room/fact-sheets/detail/immunization -coverage.

[19] R. Chapagain, "Factors affecting complementary feeding practices of Nepali mothers for 6 months to 24 months children," Journal of Nepal Health Research Council, vol. 11, no. 24, pp. 205-207, 2013.

[20] "Rupandehi District Development Committee, Rupandehi District Development Committee Profile Report 2073/74," 2020, https://dccrupandehi.gov.np/.

[21] Government of Nepal, "National planning commission secretariat, central bureau of statistics," National Population and Housing Census 2011, vol. 2, Village Development Committee/Municipality, Kathmandu, Nepal, 2012http://mofald.gov. np/mofald/userfiles/docs_206.pdf.

[22] A. H. Baral and J. Bhattarai, "Awareness and practices regarding health promotional measures of infant among mother in Kathmandu, Nepal," International Journal of Science and Research, vol. 9, no. 7, pp. 1349-1357, 2018.

[23] L. Lauria, A. Spinelli, and M. Grandolfo, "Prevalence of breastfeeding in Italy: a population based follow-up study," Annali dell'Istituto Superiore di Sanita, vol. 52, no. 3, pp. 457-461, 2016.

[24] Ministry of Health, Nepal, New ERA, and ICF, Nepal Demographic and Health Survey 2016, Ministry of Health, Nepal, Kathmandu, Nepal, 2017.

[25] D. Dharel, R. Dhungana, S. Basnet et al., "Breastfeeding practices within the first six months of age in mid-western and eastern regions of Nepal: a health facility-based cross-sectional study," BMC Pregnancy and Childbirth, vol. 20, no. 1, p. $59,2020$.
[26] V. Khanal, A. H. Lee, J. A. Scott, R. Karkee, and C. W. Binns, "Implications of methodological differences in measuring the rates of exclusive breastfeeding in Nepal: findings from literature review and cohort study," BMC Pregnancy and Childbirth, vol. 16, no. 1, pp. 389-9, 2016.

[27] D. Paudel and S. Giri, "Breast feeding practices and associated factors in Bhaktapur district of Nepal: a community based cross-sectional study among lactating mothers," Journal of the Scientific Society, vol. 41, no. 2, p. 108, 2014.

[28] V. Velusamy, P. S. Premkumar, and G. Kang, "Exclusive breastfeeding practices among mothers in urban slum settlements: pooled analysis from three prospective birth cohort studies in South India," International Breastfeeding Journal, vol. 12, no. 1, pp. 35-37, 2017.

[29] D. Tshering, M. S. Gurung, N. Wangmo, D. Pelzom, P. Tejativaddhana, and L. Dzed, "Prevalence of exclusive breastfeeding and factors associated with exclusive breastfeeding of children in Trongsa District, Bhutan," Asia Pacific Journal of Public Health, vol. 30, no. 4, pp. 369-377, 2018.

[30] G. Mekuria and M. Edris, "Exclusive breastfeeding and associated factors among mothers in Debre Markos, Northwest Ethiopia: a cross-sectional study," International Breastfeeding Journal, vol. 10, no. 1, pp. 1-7, 2015.

[31] W. Seifu, G. Assefa, and G. Egata, "Prevalence of exclusive breast feeding and its predictors among infants aged six months in Jimma Town, Southwest Ethiopia, 2013," Journal of Pediatrics \& Neonatal Care, vol. 1, no. 3, 2014.

[32] N. Subedi, S. Paudel, T. Rana, and A. Poudyal, "Infant and young child feeding practices in Chepang communities," Journal of Nepal Health Research Council, vol. 10, no. 21, pp. 141-146, 2012.

[33] A. Belachew, T. Tewabe, A. Asmare, D. Hirpo, B. Zeleke, and D. Muche, "Prevalence of exclusive breastfeeding practice and associated factors among mothers having infants less than 6 months old, in Bahir Dar, Northwest, Ethiopia: a community based cross sectional study, 2017," BMC Research Notes, vol. 11, no. 1, pp. 768-776, 2018.

[34] M. Ulak, R. K. Chandyo, L. Mellander, P. S. Shrestha, and T. A. Strand, "Infant feeding practices in Bhaktapur, Nepal: a cross-sectional, health facility based survey," International Breastfeeding Journal, vol. 7, no. 1, pp. 1-8, 2012.

[35] P. C. Joshi, M. R. Angdembe, S. K. Das, S. Ahmed, A. S. G. Faruque, and T. Ahmed, "Prevalence of exclusive breastfeeding and associated factors among mothers in rural Bangladesh: a cross-sectional study," International Breastfeeding Journal, vol. 9, no. 1, pp. 7-8, 2014.

[36] V. Khanal, A. H. Lee, R. Karkee, and C. W. Binns, "Prevalence and factors associated with prelacteal feeding in Western Nepal," Women and Birth, vol. 29, no. 1, pp. 12-17, 2016.

[37] V. Khanal and K. Sauer, "Determinants of the introduction of prelacteal feeds in rural Nepal: a cross-sectional communitybased study," Breastfeeding Medicine, vol. 8, no. 3, pp. 336-339, 2013.

[38] M. Yotebieng, J. L. Chalachala, M. Labbok, and F. Behets, "Infant feeding practices and determinants of poor breastfeeding behavior in Kinshasa, Democratic Republic of Congo: a descriptive study," International Breastfeeding Journal, vol. 8, no. 1, p. 11, 2013.

[39] E. W. Kimani-Murage, N. J. Madise, J.-C. Fotso et al., "Patterns and determinants of breastfeeding and complementary feeding practices in urban informal settlements, Nairobi Kenya," BMC Public Health, vol. 11, no. 1, p. 396, 2011.

[40] S. Bhandari, A. L. Thorne-Lyman, B. Shrestha et al., "Determinants of infant breastfeeding practices in Nepal: a 
national study," International Breastfeeding Journal, vol. 14, no. 1, p. 14, 2019.

[41] R. Kakati, S. Rahman, M. Borah, and H. Borah, "Colostrum feeding practices and its determinants among urban and rural mothers in Kamrup, Assam, India," International Journal of Research in Medical Sciences, vol. 4, no. 10, pp. 4567-4572, 2016.

[42] V. Khanal, J. Scott, A. Lee, R. Karkee, and C. Binns, "Factors associated with early initiation of breastfeeding in Western Nepal," International Journal of Environmental Research and Public Health, vol. 12, no. 8, pp. 9562-9574, 2015.

[43] R. M. Sankeshwari, A. V. Ankola, and P. S. Tangade, "Feeding habits and oral hygiene practices as determinants of early childhood caries in 3-to 5-year-old children of Belgaum City, India," vol. 10, no. 3, 2012.

[44] K. P. Gautam, M. Adhikari, R. B. Khatri, and M. D. Devkota, "Determinants of infant and young child feeding practices in Rupandehi, Nepal," BMC Research Notes, vol. 9, no. 1, pp. 135-137, 2016.

[45] M. V. Dhami, F. A. Ogbo, U. L. Osuagwu, and K. E. Agho, "Prevalence and factors associated with complementary feeding practices among children aged 6-23 months in India: a regional analysis," BMC Public Health, vol. 19, no. 1, pp. 1-16, 2019.

[46] L. Bewket Zeleke, M. Welday Gebremichael, Y. Mehretie Adinew, and K. Abebe Gelaw, "Appropriate weaning practice and associated factors among infants and young children in Northwest Ethiopia," Journal of Nutrition and Metabolism, vol. 2017, Article ID 9608315, 7 pages, 2017.

[47] M. Berisha, N. Ramadani, R. Hoxha et al., "Knowledge, attitudes and practices of mothers in kosova about complementary feeding for infant and children 6-24 months," Medical Archives, vol. 71, no. 1, p. 37, 2017.

[48] N. Ulak and K. Tiwari, "Complementary feeding practices and it's associated factors among mothers in selected urban area of Nepal," Asploro Journal of Biomedical and Clinical Case Reports, vol. 3, no. 1, pp. 6-14, 2020.

[49] J. Pang, S. W. J. L. Chua, and L. Hsu, "Current knowledge, attitude and behaviour of hand and food hygiene in a developed residential community of Singapore: a cross-sectional survey," BMC Public Health, vol. 15, no. 1, p. 577, 2015.

[50] B. Adhikari, S. Bhattarai, P. Gauro, and R. Mishra, "Awareness and practice of mother having under five children regarding prevention of childhood accident," International Journal of Health Sciences and Research, vol. 7, no. 9, pp. 134-144, 2017.

[51] M. Tsegaye, D. Ajema, S. Shiferaw, and R. Yirgu, "Level of exclusive breastfeeding practice in remote and pastoralist community, Aysaita Woreda, Afar, Ethiopia," International Breastfeeding Journal, vol. 14, no. 1, p. 6, 2019.

[52] A. H. Dagne, K. T. Anteneh, M. B. Badi, H. H. Adhanu, M. A. Ahunie, and G. L. Aynalem, "Appropriate complementary feeding practice and associated factors among mothers having children aged 6-24 months in Debre Tabor Hospital, North West Ethiopia, 2016," BMC Research Notes, vol. 12, no. 1, pp. 1-6, 2019. 